\title{
Seletividade e eficiência de herbicidas aplicados em pré-emergência na cultura da mandioca ${ }^{1}$
}

\author{
Cesar Augusto Scariot ${ }^{2}$, Neumárcio Vilanova da Costa $^{2}$, \\ Everton Paulo Bosquese ${ }^{2}$, Devair Carlos de Andrade², Daniel Adriano Sontag ${ }^{2}$
}

\begin{abstract}
Selectivity and efficiency of

pre-emergent herbicides on cassava crop

The chemical control of weeds stands out as an important tool for obtaining high yields in cassava crops. This study aimed at evaluating the selectivity and efficiency of pre-emergent herbicides on cassava ('Cascuda' cultivar) crop. The experimental design was randomized blocks, with ten treatments and four replications. The treatments consisted of clomazone $\left(900 \mathrm{~g} \mathrm{ha}^{-1}\right.$ and $\left.1,080 \mathrm{~g} \mathrm{ha}^{-1}\right)$, flumioxazin $\left(60 \mathrm{~g} \mathrm{ha}^{-1}\right)$, sulfentrazone (600 $\left.\mathrm{g} \mathrm{ha}^{-1}\right)$, S-metolachlor $\left(1,920 \mathrm{~g} \mathrm{ha}^{-1}\right)$, clomazone + flumioxazin $(900+$ $\left.50 \mathrm{~g} \mathrm{ha}^{-1}\right)$, clomazone + sulfentrazone $\left(900+500 \mathrm{~g} \mathrm{ha}^{-1}\right)$ and clomazone + S-metolachlor $\left(900+1,440 \mathrm{~g} \mathrm{ha}^{-1}\right)$, as well as a weeded and a non-weeded control. The weed community was composed by 9 families and 12 species, with the Asteraceae and Poaceae families presenting the highest number of species. The pre-emergent herbicides were selective for 'Cascuda' cultivar cassava plants. The herbicides were effective in controlling weeds, with flumioxazin $\left(60 \mathrm{~g} \mathrm{ha}^{-1}\right)$, sulfentrazone $\left(600 \mathrm{~g} \mathrm{ha}^{-1}\right)$, S-metolachlor $\left(1,920 \mathrm{~g} \mathrm{ha}^{-1}\right)$ and the mixtures of clomazone + flumioxazin $\left(900+50 \mathrm{~g} \mathrm{ha}^{-1}\right)$, clomazone + sulfentrazone $(900+$ $\left.500 \mathrm{~g} \mathrm{ha}^{-1}\right)$ and clomazone + S-metolachlor $\left(900+1,440 \mathrm{~g} \mathrm{ha}^{-1}\right)$ presenting the highest residual effect.
\end{abstract}

KEY-WORDS: Manihot esculenta L. Crantz; Asteraceae; Poaceae; weed.

\section{INTRODUÇÃO}

No Brasil, a mandioca apresenta característica de produto de subsistência e, também, de matéria-prima agroindustrial, sendo cultivada em todas as regiões do País (Borges et al. 2002, Felipe et al. 2010). O Estado do Paraná destaca-se, dentre os principais produtores de mandioca, com área cultivada em torno de 179,6 mil hectares e produção de 4,1 milhões de toneladas de raízes, na safra 2011/2012, com produtividade média de 22,6 t ha-1 (IBGE 2012).

\section{RESUMO}

O manejo químico das plantas daninhas destaca-se como ferramenta importante para a garantia de altos rendimentos da mandiocultura. Este estudo objetivou avaliar a seletividade e eficiência de herbicidas, aplicados em pré-emergência, na cultura da mandioca cv. 'Cascuda'. O delineamento experimental utilizado foi o de blocos ao acaso, com dez tratamentos e quatro repetições. Os tratamentos utilizados foram: clomazone $\left(900 \mathrm{~g} \mathrm{ha}^{-1}\right.$ e $\left.1.080 \mathrm{~g} \mathrm{ha}^{-1}\right)$, flumioxazin $\left(60 \mathrm{~g} \mathrm{ha}^{-1}\right)$, sulfentrazone (600 $\left.\mathrm{g} \mathrm{ha}^{-1}\right)$, S-metolachlor (1.920 $\left.\mathrm{g} \mathrm{ha}^{-1}\right)$, clomazone + flumioxazin $\left(900+50 \mathrm{~g} \mathrm{ha}^{-1}\right)$, clomazone + sulfentrazone $\left(900+500 \mathrm{~g} \mathrm{ha}^{-1}\right)$ e clomazone + S-metolachlor $(900+$ $1.440 \mathrm{~g} \mathrm{ha}^{-1}$ ), além de uma testemunha sem capina e outra capinada. A comunidade de plantas daninhas foi composta por 9 famílias e 12 espécies, destacando-se as famílias Asteraceae e Poaceae, com o maior número de espécies. Os herbicidas apresentaram-se seletivos às plantas de mandioca cv. 'Cascuda', quando aplicados em pré-emergência. Os herbicidas foram eficientes no controle das plantas daninhas, sendo que o flumioxazin $\left(60 \mathrm{~g} \mathrm{ha}^{-1}\right)$, sulfentrazone $\left(600 \mathrm{~g} \mathrm{ha}^{-1}\right)$, S-metolachlor $\left(1.920 \mathrm{~g} \mathrm{ha}^{-1}\right)$ e as misturas clomazone + flumioxazin $(900+$ $\left.50 \mathrm{~g} \mathrm{ha}^{-1}\right)$, clomazone + sulfentrazone $\left(900+500 \mathrm{~g} \mathrm{ha}^{-1}\right)$ e clomazone + S-metolachlor $\left(900+1.440 \mathrm{~g} \mathrm{ha}^{-1}\right)$ apresentaram maior efeito residual.

PALAVRAS-CHAVE: Manihot esculenta L. Crantz; Asteraceae; Poaceae; planta daninha.

A maior parte da produção de mandioca do Paraná destina-se à indústria de fécula e farinha, destacando-se a cv. 'Cascuda', dentre as mais plantadas (Felipe et al. 2010). Contudo, assim como toda cultura, as plantas de mandioca têm seu crescimento e desenvolvimento afetado pela interferência de plantas daninhas, que, consequentemente, reduzem a produtividade e viabilidade econômica da cultura (Silva et al. 2009, Curcelli et al. 2010).

A convivência da comunidade de plantas daninhas com a cultura da mandioca pode reduzir

1. Trabalho recebido em mar./2013 e aceito para publicação em set./2013 ( $\mathrm{n}^{\circ}$ registro: PAT 22892).

2. Universidade Estadual do Oeste do Paraná (Unioeste), Centro de Ciências Agrárias, Marechal Cândido Rondon, PR, Brasil.

E-mails: cesarscariot@hotmail.com,neumarciovc@hotmail.com, everton_spi@hotmail.com,devair.carlos.5@facebook.com, danielsontag@hotmail.com. 
a produção de raízes em $89,8-100 \%$ (Peressin et al. 1998, Alabi et al. 2001, Chikoye et al. 2001, Johanns \& Contiero 2006, Albuquerque et al. 2008). Desta maneira, o controle químico apresenta-se como excelente alternativa para o manejo das plantas daninhas, na cultura da mandioca, por permitir a intervenção em grandes áreas, com pouca dependência de mão de obra e rapidez na aplicação (Silva et al. 2012, Silveira et al. 2012).

No Brasil, apenas os herbicidas ametryna + clomazone, clethodim, clomazone, isoxaflutole e metribuzin são registrados para a cultura da mandioca (Rodrigues \& Almeida 2005). No entanto, os herbicidas flumioxazin, sulfentrazone e S-metolachlor apresentam seletividade à mandioca e podem ser incluídos em programas de manejo de plantas daninhas (Oliveira Júnior et al. 2001, Silva et al. 2009, Biffe et al. 2010, Silveira et al. 2012).

Apesar de o controle químico apresentar vantagens sobre os demais métodos de controle de plantas daninhas, deve-se ressaltar que este só pode ser praticado com o uso de herbicidas seletivos para a cultura. Segundo Velini et al. (2000), para ser recomendado de forma definitiva e indiscriminada, para determinada cultura, um herbicida deve demonstrar seletividade às cultivares mais comuns desta cultura. Estes autores definem a seletividade como a capacidade de um determinado herbicida eliminar as plantas daninhas encontradas em uma cultura, sem reduzir-lhe a produtividade.

Devido ao fato de a mandioca ser uma cultura que não apresenta grande impacto no cenário produtivo nacional, quando comparada a culturas de maior expressão como a soja, milho e cana-de-açúcar, não existe grande interesse, por parte de empresas de defensivos, em registrar produtos para esta cultura (Silva et al. 2009). Destaca-se, ainda, que a mandiocultura apresenta elevada importância econômica em regiões farinheiras, como o norte de Minas e as regiões Norte e Nordeste, além da fécula, em regiões do Centro-Sul do País.

Existem poucos estudos sobre métodos de controle de plantas daninhas envolvendo herbicidas seletivos, para a cultura da mandioca, principalmente para a aplicação em pré-emergência da cultura. Assim, objetivou-se avaliar a seletividade e a eficiência de herbicidas aplicados em pré-emergência, na cultura da mandioca cv. 'Cascuda'.

\section{MATERIAL E MÉTODOS}

O experimento foi instalado na Estação Experimental do Instituto Agronômico do Paraná (Iapar), no município de Porto Mendes (PR). A área foi anteriormente cultivada com milho (semeadura em março/2011), no espaçamento de $0,7 \mathrm{~m}$ entre as linhas, com 3,5 plantas por metro. Após a colheita do milho, realizou-se a dessecação das plantas daninhas na área (setembro/2011), utilizando-se o glyphosate (ZAPP Qi 620), na dose de 2,0 $\mathrm{L} \mathrm{ha}^{-1}$ do produto comercial.

O solo, classificado como Latossolo Vermelho eutroférrico (LVef) (Embrapa 2006), foi preparado utilizando-se uma aração e duas gradagens, sendo que a sua análise apresentou as seguintes características: $\mathrm{pH}\left(\mathrm{CaCl}_{2}\right)=5,6$; matéria orgânica $=$ $22,6 \mathrm{~g} \mathrm{dm}^{-3} ; \mathrm{P}=4,0 \mathrm{mg} \mathrm{dm}^{-3} ; \mathrm{H}+\mathrm{Al}=4,61 \mathrm{cmol}_{\mathrm{c}} \mathrm{dm}^{-3}$; $\mathrm{K}=0,51 \mathrm{cmol}_{\mathrm{c}} \mathrm{dm}^{-3} ; \mathrm{Ca}=8,09 \mathrm{cmol}_{\mathrm{c}} \mathrm{dm}^{-3} ; \mathrm{Mg}=$ $1,88 \mathrm{cmol}_{\mathrm{c}} \mathrm{dm}^{-3} ; \mathrm{SB}=10,48 \mathrm{cmol}_{\mathrm{c}} \mathrm{dm}^{-3} ; \mathrm{CTC}=$ $15,09 \mathrm{cmol}_{\mathrm{c}} \mathrm{dm}^{-3} ; \mathrm{V}=69,45 \%$; areia $=15,0 \%$; silte $=$ $30,0 \%$; argila $=55,0 \%$.

O plantio da variedade cv. 'Cascuda' foi realizado em 15/09/2011, com o auxílio de plantadora mecanizada, em linha, no espaçamento de $0,9 \mathrm{~m} \mathrm{x}$ $0,7 \mathrm{~m}$. O delineamento experimental utilizado foi o de blocos ao acaso, com dez tratamentos e quatro repetições (Tabela 1). As parcelas foram constituídas de cinco linhas de mandioca, espaçadas em $0,9 \mathrm{~m} \mathrm{x}$ $7,0 \mathrm{~m}$ de comprimento $\left(4,5 \mathrm{~m} \times 7,0 \mathrm{~m}=31,5 \mathrm{~m}^{2}\right)$. Os dados de temperatura média $\left({ }^{\circ} \mathrm{C}\right)$ e precipitação $(\mathrm{mm})$, durante o período de condução do experimento, estão descritos na Figura 1.

Foi utilizado um pulverizador costal, pressurizado a $\mathrm{CO}_{2}$ e munido de barra com quatro pontas de jato plano (modelo Jacto 110-LD-02), espaçadas entre si em $50 \mathrm{~cm}$, com pressão de trabalho de $45 \mathrm{Lb} \mathrm{pol}^{-2}$ e consumo de calda equivalente a $200 \mathrm{~L} \mathrm{ha}^{-1}$.

As aplicações foram realizadas no final da tarde de 22/09/2011, com as condições de temperatura, umidade relativa do ar e velocidade do vento de $30^{\circ} \mathrm{C}, 50 \%$ e $2 \mathrm{~km} \mathrm{~h}^{-1}$, respectivamente. No momento da aplicação, o solo encontrava-se seco, e cerca de $20 \%$ das manivas apresentavam início de brotação das gemas (brotos $=1 \mathrm{~cm}$ ) ou encontravam-se não emergidas. A emergência das plantas ocorreu, aproximadamente, aos 20 dias após a aplicação (DAA).

As avaliações de injúrias, nas plantas de mandioca, e de controle das plantas daninhas foram realizadas de forma visual, utilizando-se uma escala percentual de notas, em que 0 (zero) correspondeu 
Tabela 1. Tratamentos avaliados no experimento.

\begin{tabular}{llr}
\hline \multicolumn{1}{c}{ Nome comercial } & \multicolumn{1}{c}{ Nome comum } & Dose $\left(\mathrm{g} \mathrm{ha}^{-1}\right)$ \\
\hline Gamit 360 CS & Clomazone & 900 \\
Gamit 360 CS & Clomazone & 1.080 \\
Flumyzin 500 & Flumioxazin & 60 \\
Boral 500 SC & Sulfentrazone & 600 \\
Dual Gold & S-metolachlor & 1.920 \\
Gamit 360 CS + Flumyzin 500 & Clomazone + flumioxazin & $900+50$ \\
Gamit 360 CS + Boral 500 SC & Clomazone + sulfentrazone & $900+500$ \\
Gamit 360 CS + Dual Gold & Clomazone + S-metolachlor & $900+1.440$ \\
Testemunha sem capina & - & - \\
Testemunha capinada & - & - \\
\hline
\end{tabular}

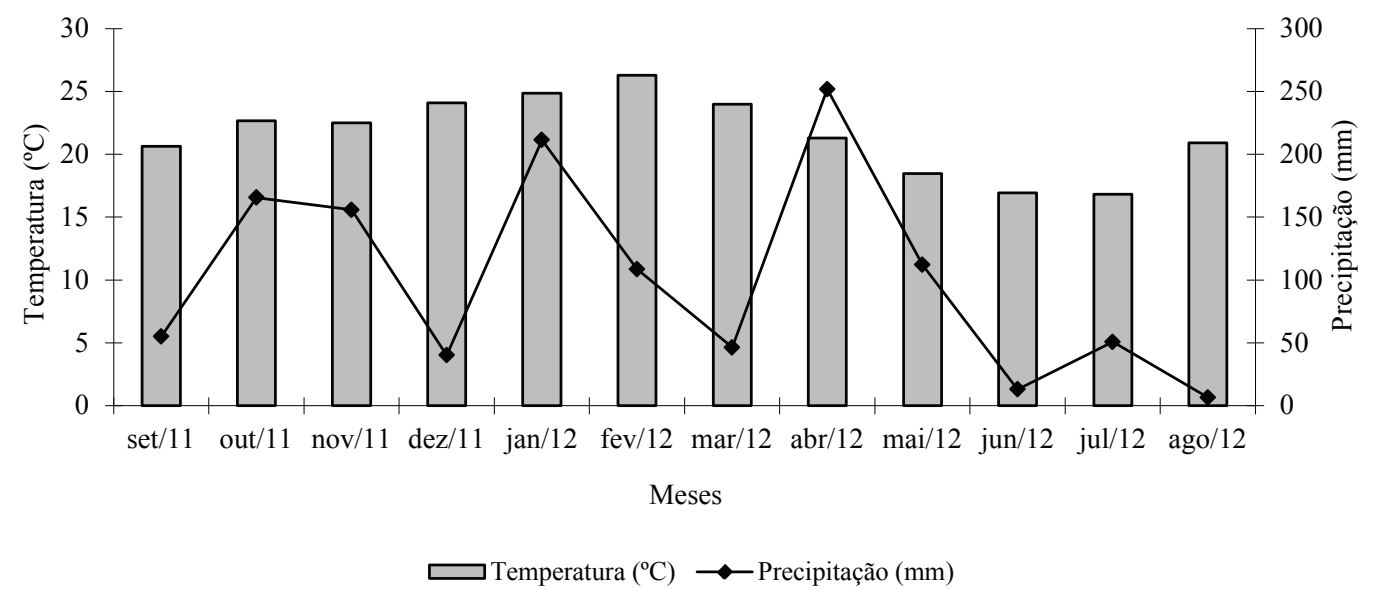

Figura 1. Temperatura média $\left({ }^{\circ} \mathrm{C}\right)$ e precipitação (mm), durante o período de condução do experimento (Porto Mendes, PR, 2011/2012).

a nenhuma injúria demonstrada pela planta de mandioca ou controle das plantas daninhas, e 100 (cem) à morte das plantas de mandioca ou controle das plantas daninhas (SBCPD 1995). Os critérios usados para o estabelecimento das notas foram: inibição do crescimento, quantidade e uniformidade das injúrias ou controle, capacidade de rebrota das plantas e quantidade de plantas mortas. As avaliações foram realizadas aos 47, 63, 88 e 105 dias após a aplicação dos herbicidas (DAA).

A caracterização da comunidade de plantas daninhas foi realizada aos $105 \mathrm{DAA}$, por meio do método do quadrado inventário, com o auxílio de quadros de $0,25 \mathrm{~m}^{2}(0,5 \mathrm{~m} \times 0,5 \mathrm{~m})$, lançados uma vez, ao acaso, em cada parcela. As plantas daninhas foram contadas e identificadas segundo a família, gênero e espécie. A partir da contagem das espécies presentes, foram calculados os seguintes parâmetros fitossociológicos: densidade relativa (Dr), frequência relativa (Fr), abundância relativa (Ar) e índice de importância relativa (Ir), segundo as fórmulas propostas por Mueller-Dombois \& Ellemberg (1974) e Braun-Blanquet (1979). As plantas daninhas coletadas foram secas em estufa de circulação forçada de ar, a $60^{\circ} \mathrm{C}$, por 72 horas, e, em seguida, pesadas em balança de precisão $(0,001 \mathrm{~g})$.

Por ocasião da colheita das raízes de mandioca (16/08/2012 - ciclo de 11 meses), coletaram-se as plantas das três linhas centrais das parcelas, desconsiderando-se uma planta de cada extremidade das linhas. Após a pesagem das raízes, determinou-se a produtividade $\left(\mathrm{t} \mathrm{ha} \mathrm{H}^{-1}\right)$. Foi coletada, de cada parcela, uma amostra de 5,0 kg de raízes, para a determinação da percentagem de fécula, utilizando-se o método da balança hidrostática (Grossman \& Freitas 1950).

Os resultados obtidos foram submetidos à análise de variância, pelo teste $\mathrm{F}$, sendo as médias analisadas estatisticamente pelo teste de média LSD, a $5 \%$. Os dados de percentagem de controle das plantas daninhas foram transformados em arco seno $\sqrt{ } \mathrm{x} / 100$. 


\section{RESULTADOS E DISCUSSÃO}

Verificou-se, no $47^{\circ}$ DAA, que o controle das plantas daninhas foi superior a $90 \%$, em todos os tratamentos avaliados (Tabela 2). Contudo, a partir do $63^{\circ} \mathrm{DAA}$, os tratamentos com clomazone $\left(900 \mathrm{~g} \mathrm{ha}^{-1}\right.$ e $1.080 \mathrm{~g} \mathrm{ha}^{-1}$ ) apresentaram redução na eficiência de controle das plantas daninhas, porém, dentro de um controle satisfatório ou eficiente, sendo mais evidente aos 88 DAA, quando proporcionaram eficiência de $65 \%$ e $71 \%$, respectivamente.

Aos 105 DAA, o flumioxazin (60 $\left.\mathrm{g} \mathrm{ha}^{-1}\right)$, sulfentrazone (600 $\left.\mathrm{g} \mathrm{ha}^{-1}\right)$ e S-metolachlor (1.920 $\left.\mathrm{g} \mathrm{ha}^{-1}\right)$ proporcionaram excelente controle das plantas daninhas, bem como as misturas clomazone + flumioxazin $\left(900+50 \mathrm{~g} \mathrm{ha}^{-1}\right)$, clomazone + sulfentrazone $\left(900+500 \mathrm{~g} \mathrm{ha}^{-1}\right)$ e clomazone + S-metolachlor $\left(900+1.440 \mathrm{~g} \mathrm{ha}^{-1}\right)$, que apresentaram eficiência superior a $90 \%$. Não foram constatados sintomas visuais de fitointoxicação nas plantas de mandioca cv. 'Cascuda', após a aplicação dos herbicidas. Este fato pode ser explicado devido à demora das plantas para emergirem do solo (emergência aos 20 DAA), o que expôs menos pontos de absorção dos herbicidas, bem como à ocorrência da adsorção das moléculas ao solo, pela presença de elevados teores de argila. Outro ponto a ser destacado seria a baixa ocorrência de chuvas logo após o plantio (Figura 1), o que pode ter minimizado a absorção dos herbicidas.

Oliveira Júnior et al. (2001) verificaram que o flumioxazin (42 $\left.\mathrm{g} \mathrm{ha}^{-1}\right)$ e o metolachlor $\left(2.000 \mathrm{~g} \mathrm{ha}^{-1}\right)$ provocaram sintomas leves de fitointoxicação na mandioca 'Espeto', em aplicações de pré-emergência, em solo de textura arenosa, aos 28 dias após o plantio (momento em que, praticamente, todos os brotos estavam emergidos), enquanto o sulfentrazone ( $\left.600 \mathrm{~g} \mathrm{ha}^{-1}\right)$ provocou forte descoloração (amarelecimento) ou deformação, com leve necrosamento de algumas folhas, especialmente nas margens, acompanhado de deformação em folhas e brotos, para o mesmo período.

Para a densidade e massa seca das plantas daninhas, pôde-se constatar que os dados corroboram os de eficiência de controle, evidenciando que os herbicidas flumioxazin $\left(60 \mathrm{~g} \mathrm{ha}^{-1}\right)$, sulfentrazone $\left(600 \mathrm{~g} \mathrm{ha}^{-1}\right)$, S-metolachlor $\left(1.920 \mathrm{~g} \mathrm{ha}^{-1}\right)$ e as misturas clomazone + flumioxazin $\left(900+50 \mathrm{~g} \mathrm{ha}^{-1}\right)$, clomazone + sulfentrazone $\left(900+500 \mathrm{~g} \mathrm{ha}^{-1}\right)$ e clomazone + S-metolachlor $\left(900+1.440 \mathrm{~g} \mathrm{ha}^{-1}\right)$ promoveram as maiores reduções, principalmente na densidade das plantas daninhas, quando comparados com a testemunha sem capina (Tabela 3 ).

A comunidade infestante presente na área experimental foi composta por 9 famílias e 12 gêneros, com as famílias Asteraceae e Poaceae apresentando o maior número de espécies. A classe eudicotiledôneas estava representada com $75,0 \%$ das espécies presentes na área (Tabela 4). De maneira geral, verificou-se, nos tratamentos que apresentaram menor controle (clomazone a $900 \mathrm{~g} \mathrm{ha}^{-1} \mathrm{e} 1.080 \mathrm{~g} \mathrm{ha}^{-1}$ ), maior predominância das espécies Commelina benghalensis, Euphorbia heterophylla, Leonurus sibiricus e Phyllanthus tenellus, aos 105 DAA (Tabela 5). Oli-

Tabela 2. Percentagem geral de controle das plantas daninhas, após a aplicação de herbicidas em pré-emergência (Porto Mendes, PR, 2011/2012).

\begin{tabular}{lcclcc}
\hline \multicolumn{1}{c}{ Tratamento } & Dose $\left(\mathrm{g} \mathrm{ha}^{-1}\right)$ & $47 \mathrm{DAA}$ & $63 \mathrm{DAA}$ & $88 \mathrm{DAA}$ & $105 \mathrm{DAA}$ \\
\hline Clomazone & 900 & $92,7(74,4) \mathrm{cd}$ & $86,7(68,8) \mathrm{d}$ & $65,0(54,1) \mathrm{c}$ & $62,7(52,7) \mathrm{c}$ \\
Clomazone & 1.080 & $92,3(74,0) \mathrm{d}$ & $88,3(70,5) \mathrm{cd}$ & $71,0(57,9) \mathrm{c}$ & $66,7(55,1) \mathrm{c}$ \\
Flumioxazin & 60 & $93,7(75,9) \mathrm{bcd}$ & $89,7(71,5) \mathrm{bcd}$ & $80,3(63,7) \mathrm{bc}$ & $79,7(63,2) \mathrm{bc}$ \\
Sulfentrazone & 600 & $97,0(80,2) \mathrm{ab}$ & $93,7(76,6) \mathrm{abc}$ & $90,7(73,6) \mathrm{ab}$ & $90,3(73,2) \mathrm{ab}$ \\
S-metolachlor & 1.920 & $96,3(79,3) \mathrm{abc}$ & $94,0(76,3) \mathrm{abcd}$ & $89,3(71,1) \mathrm{ab}$ & $88,3(70,1) \mathrm{ab}$ \\
Clomazone + flumioxazin & $900+50$ & $98,8(84,5) \mathrm{a}$ & $96,5(81,3) \mathrm{a}$ & $93,5(78,0) \mathrm{a}$ & $93,0(78,3) \mathrm{a}$ \\
Clomazone + sulfentrazone & $900+500$ & $98,0(82,5) \mathrm{a}$ & $95,5(78,6) \mathrm{ab}$ & $92,3(76,2) \mathrm{a}$ & $91,5(75,5) \mathrm{ab}$ \\
Clomazone + S-metolachlor & $900+1.440$ & $98,3(83,9) \mathrm{a}$ & $97,8(82,7) \mathrm{a}$ & $93,3(77,5) \mathrm{a}$ & $91,8(76,0) \mathrm{ab}$ \\
Testemunha sem capina & - & $0,0(00,0) \mathrm{e}$ & $0,0(00,0) \mathrm{e}$ & $0,0(00,0) \mathrm{d}$ & $0,0(00,0) \mathrm{d}$ \\
Testemunha capinada & - & - & - & - & - \\
\hline $\mathrm{F}_{\text {Tratamentos }}$ & - & $227,999^{* *}$ & $94,132^{* *}$ & $33,727^{* *}$ & $29,860^{* *}$ \\
\hline $\mathrm{F}_{\text {Blocos }}$ & - & $0,073^{\mathrm{ns}}$ & $0,495^{\mathrm{ns}}$ & $0,314^{\mathrm{ns}}$ & $0,447^{\mathrm{ns}}$ \\
\hline CV $(\%)$ & - & 5,02 & 7,87 & 13,80 & 12,360 \\
\hline DMS & - & 5,168 & 7,734 & 14,82 \\
\hline
\end{tabular}

Médias seguidas de mesma letra, na coluna, não diferem, estatisticamente, entre si, pelo teste LSD ( $p>0,05)$. Os dados de percentagem de controle foram transformados em arco seno $\sqrt{\mathrm{x}} / 100$ (entre parêntesis). DAA: dias após a aplicação. ${ }^{* *} \mathrm{e}^{\mathrm{ns}}$ significativo a $1 \%$ e não significativo, respectivamente. 
veira Júnior et al. (2001) observaram que o flumioxazin $\left(42 \mathrm{~g} \mathrm{ha}^{-1}\right)$ foi ineficiente no controle de C. benghalensis. Entretanto, verificaram que o metolachlor $\left(2.000 \mathrm{~g} \mathrm{ha}^{-1}\right)$ e o sulfentrazone $\left(600 \mathrm{~g} \mathrm{ha}^{-1}\right)$ foram eficientes no controle desta espécie.

Kelly et al. (2006) concluíram que o flumioxazin (36-109 $\mathrm{g} \mathrm{ha}^{-1}$ ), aplicado em pré-emergência, mostrou-se eficiente em mistura com clomazone $\left(840 \mathrm{~g} \mathrm{ha}^{-1}\right)$, para controlar plantas daninhas de folha larga e melhorar o controle de gramíneas, em áreas de produção de tubérculos de batata-doce (Ipomoea batatas).

Tabela 3. Densidade e massa seca das plantas daninhas, aos 105 dias após a aplicação dos herbicidas em préemergência na mandioca cv. 'Cascuda' (Porto Mendes, PR, 2011/2012).

\begin{tabular}{|c|c|c|c|}
\hline Tratamento & $\begin{array}{l}\text { Dose } \\
\mathrm{g} \mathrm{ha}^{-1}\end{array}$ & $\begin{array}{l}\text { Densidade } \\
\text { planta } \mathrm{m}^{-2}\end{array}$ & $\frac{\text { Massa seca }}{\mathrm{g} \mathrm{m}^{-2}}$ \\
\hline Clomazone & 900 & $16 \mathrm{a}$ & 96,0 \\
\hline Clomazone & 1.080 & $17 \mathrm{a}$ & 63,9 \\
\hline Flumioxazin & 60 & $7 \mathrm{~b}$ & 159,6 \\
\hline Sulfentrazone & 600 & $2 \mathrm{~b}$ & 58,0 \\
\hline S-metolachlor & 1.920 & $7 \mathrm{~b}$ & 54,6 \\
\hline Clomazone + flumioxazin & $900+50$ & $3 \mathrm{~b}$ & 40,0 \\
\hline Clomazone + sulfentrazone & $900+500$ & $3 \mathrm{~b}$ & 10,3 \\
\hline Clomazone + S-metolachlor & $900+1.440$ & $3 \mathrm{~b}$ & 121,3 \\
\hline Testemunha sem capina & & $21 \mathrm{a}$ & 248,0 \\
\hline Testemunha capinada & & - & - \\
\hline $\mathrm{F}_{\text {Tratamentos }}$ & & $5,720 * *$ & $2,134^{\mathrm{ns}}$ \\
\hline $\mathrm{F}_{\text {Blocos }}$ & & $2,167^{\text {ns }}$ & $2,619^{\text {ns }}$ \\
\hline CV $(\%)$ & & 69,16 & 105,37 \\
\hline DMS & & 8,859 & - \\
\hline
\end{tabular}

Para os demais tratamentos [flumioxazin $\left(60 \mathrm{~g} \mathrm{ha}^{-1}\right)$, sulfentrazone (600 $\left.\mathrm{g} \mathrm{ha}^{-1}\right)$, S-metolachlor $\left(1.920 \mathrm{~g} \mathrm{ha}^{-1}\right) \mathrm{e}$ as misturas clomazone + flumioxazin $\left(900+50 \mathrm{~g} \mathrm{ha}^{-1}\right)$, clomazone + sulfentrazone $(900+$ $\left.500 \mathrm{~g} \mathrm{ha}^{-1}\right)$ e clomazone + S-metolachlor $(900+$ $\left.1.440 \mathrm{~g} \mathrm{ha}^{-1}\right)$ ], as espécies que apresentaram maior índice de importância relativa foram Bidens pilosa, C. benghalensis, Emilia fosbergii, E. heterophylla, Leucena sp., P. tenellus, Richhardia brasiliensis e Sorghum halepense.

Para os dados de produtividade de raízes, percentagem de fécula e densidade de plantas de mandioca, observou-se que os herbicidas não diferiram, significativamente, das testemunhas avaliadas (Tabela 6). Da mesma forma, os herbicidas não reduziram o número de plantas de mandioca na linha de plantio.

A mandioca apresenta alta rusticidade, contudo, o grau de interferência da comunidade de plantas daninhas sobre a cultura foi considerado alto, uma vez que houve redução na produtividade e percentagem de fécula de $47,02 \%$ e $28,18 \%$, respectivamente, quando comparadas às médias das parcelas sem capina e capinada.

De acordo com Oliveira Júnior et al. (2001), o flumioxazin (42 $\left.\mathrm{g} \mathrm{ha}^{-1}\right)$, metolachlor $\left(2.000 \mathrm{~g} \mathrm{ha}^{-1}\right)$ e sulfentrazone $\left(600 \mathrm{~g} \mathrm{ha}^{-1}\right)$, aplicados em condições de solo arenoso, na pré-emergência da mandioca 'Espeto', promoveram, respectivamente, reduções de $27,6 \%, 33,6 \%$ e $63,0 \%$ na produção de raízes, quando comparados com a testemunha capinada. Estes resultados podem ser justificados devido ao fato de o flumioxazin (Kow 2,55), metolachlor (Kow $3,05)$ e sulfentrazone (Kow 1,48) apresentarem va-

Tabela 4. Relação das espécies de plantas daninhas presentes na área experimental, aos 105 dias após a aplicação dos herbicidas em pré-emergência na mandioca cv. 'Cascuda' (Porto Mendes, PR, 2011/2012).

\begin{tabular}{clll}
\hline Classificação & \multicolumn{1}{c}{ Família } & \multicolumn{1}{c}{ Nome científico } & Nome comum \\
\hline & Asteraceae & Bidens pilosa & Picão-preto \\
& Asteraceae & Emilia fosbergii & Falsa-serralha \\
& Asteraceae & Galinsoga parviflora & Picão-branco \\
& Euphorbiaceae & Euphorbia heterophylla & Leiteiro \\
& Fabaceae & Leucaena sp. & Leucena \\
& Lamiaceae & Leonurus sibiricus & Rubim \\
& Malvaceae & Sida sp. & Guanxuma \\
& Phyllanthaceae & Phyllanthus tenellus & Quebra-pedra \\
& Rubiaceae & Richhardia brasiliensis & Poaia branca \\
\hline \multirow{3}{*}{ Monocotiledônea } & Commelinaceae & Commelina benghalensis & Trapoeraba \\
& Poaceae & Panicum maximum & Capim-colonião \\
& Poaceae & Sorghum halepense & Capim-massambará \\
\hline
\end{tabular}


Tabela 5. Dados de frequência, densidade, abundância e índice de importância relativa das plantas daninhas, aos 105 dias após a aplicação dos herbicidas em pré-emergência na mandioca cv. 'Cascuda' (Porto Mendes, PR, 2011/2012).

\begin{tabular}{|c|c|c|c|c|c|c|}
\hline \multirow[t]{2}{*}{ Tratamento } & Dose & \multirow[t]{2}{*}{ Nome científico } & $\begin{array}{c}\text { Frequência } \\
\text { relativa }\end{array}$ & $\begin{array}{c}\text { Densidade } \\
\text { relativa }\end{array}$ & $\begin{array}{c}\text { Abundância } \\
\text { relativa }\end{array}$ & $\begin{array}{c}\text { Importância } \\
\text { relativa }\end{array}$ \\
\hline & $\mathrm{g} \mathrm{ha}^{-1}$ & & \multicolumn{4}{|c|}{$\%$} \\
\hline \multirow{5}{*}{ Clomazone } & \multirow{5}{*}{900} & C. benghalensis & 11,1 & 18,8 & 36,4 & 22,1 \\
\hline & & L. sibiricus & 22,2 & 12,5 & 12,1 & 15,6 \\
\hline & & P. tenellus & 44,4 & 56,3 & 27,3 & 42,7 \\
\hline & & E. heterophylla & 11,1 & 6,3 & 12,1 & 9,8 \\
\hline & & R. brasiliensis & 11,1 & 6,3 & 12,1 & 9,8 \\
\hline \multirow{4}{*}{ Clomazone } & \multirow{4}{*}{1.080} & C. benghalensis & 28,6 & 11,8 & 12,5 & 17,6 \\
\hline & & E. heterophylla & 14,3 & 11,8 & 25,0 & 17,0 \\
\hline & & L. sibiricus & 14,3 & 5,9 & 12,5 & 10,9 \\
\hline & & P. tenellus & 42,9 & 70,6 & 50,0 & 54,5 \\
\hline \multirow{4}{*}{ Flumioxazin } & \multirow{4}{*}{60} & B. pilosa & 16,7 & 14,3 & 23,1 & 18,0 \\
\hline & & E. heterophylla & 16,7 & 14,3 & 23,1 & 18,0 \\
\hline & & P. maximum & 16,7 & 14,3 & 23,1 & 18,0 \\
\hline & & C. benghalensis & 50,0 & 57,1 & 30,8 & 46,0 \\
\hline \multirow{2}{*}{ Sulfentrazone } & \multirow{2}{*}{600} & B. pilosa & 50,0 & 50,0 & 50,0 & 50,0 \\
\hline & & E. heterophylla & 50,0 & 50,0 & 50,0 & 50,0 \\
\hline \multirow{4}{*}{ S-metalachlor } & \multirow{4}{*}{1.920} & E. heterophylla & 25,0 & 42,9 & 42,9 & 36,9 \\
\hline & & C. benghalensis & 25,0 & 14,3 & 14,3 & 17,9 \\
\hline & & E. fosbergii & 25,0 & 14,3 & 14,3 & 17,9 \\
\hline & & Leucena sp. & 25,0 & 28,6 & 28,6 & 27,4 \\
\hline \multirow{2}{*}{ Clomazone + flumioxazin } & \multirow{2}{*}{$900+50$} & Leucena sp. & 50,0 & 33,3 & 33,3 & 38,9 \\
\hline & & C. benghalensis & 50,0 & 66,7 & 66,7 & 61,1 \\
\hline \multirow{3}{*}{ Clomazone + sulfentrazone } & \multirow{3}{*}{$900+500$} & R. brasiliensis & 33,3 & 33,3 & 33,3 & 33,3 \\
\hline & & P. tenellus & 33,3 & 33,3 & 33,3 & 33,3 \\
\hline & & Leucena sp. & 33,3 & 33,3 & 33,3 & 33,3 \\
\hline \multirow{3}{*}{ Clomazone + S-metalachlor } & \multirow{3}{*}{$900+1.440$} & S. halepense & 33,3 & 33,3 & 33,3 & 33,3 \\
\hline & & P. tenellus & 33,3 & 33,3 & 33,3 & 33,3 \\
\hline & & C. benghalensis & 33,3 & 33,3 & 33,3 & 33,3 \\
\hline \multirow{5}{*}{ Tratamento sem capina } & \multirow{5}{*}{-} & Sida $\mathrm{sp}$ & 33,3 & 19,0 & 13,8 & 22,1 \\
\hline & & C. benghalensis & 11,1 & 9,5 & 20,7 & 13,8 \\
\hline & & R. brasiliensis & 11,1 & 4,8 & 10,3 & 8,7 \\
\hline & & G. parviflora & 11,1 & 4,8 & 10,3 & 8,7 \\
\hline & & P. tenellus & 33,3 & 61,9 & 44,8 & 46,7 \\
\hline
\end{tabular}

Tabela 6. Produtividade, percentagem de fécula nas raízes e densidade de plantas, após a aplicação dos herbicidas em pré-emergência na mandioca cv. 'Cascuda' (Porto Mendes, PR, 2011/2012).

\begin{tabular}{|c|c|c|c|c|}
\hline \multirow{2}{*}{ Tratamento } & Dose & Produção de raízes & Fécula & Mandioca \\
\hline & $\mathrm{g} \mathrm{ha}^{-1}$ & $\mathrm{t} \mathrm{ha}^{-1}$ & $\%$ & planta $\mathrm{m}^{-1}$ \\
\hline Clomazone & 900 & 22,6 & 21,1 & 1,4 \\
\hline Clomazone & 1.080 & 23,2 & 16,4 & 1,3 \\
\hline Flumioxazin & 60 & 40,0 & 22,8 & 1,3 \\
\hline Sulfentrazone & 600 & 26,9 & 16,1 & 1,4 \\
\hline S-metolachlor & 1.920 & 24,4 & 16,8 & 1,3 \\
\hline Clomazone + flumioxazin & $900+50$ & 23,4 & 21,5 & 1,3 \\
\hline Clomazone + sulfentrazone & $900+500$ & 27,4 & 21,6 & 1,3 \\
\hline Clomazone + S-metolachlor & $900+1.440$ & 30,9 & 21,3 & 1,3 \\
\hline Testemunha sem capina & & 16,9 & 15,8 & 1,3 \\
\hline Testemunha capinada & & 31,9 & 22,0 & 1,3 \\
\hline $\mathrm{F}_{\text {Tratamentos }}$ & & $1,114^{\mathrm{ns}}$ & $1,012^{\mathrm{ns}}$ & $0,539^{\text {ns }}$ \\
\hline $\mathrm{F}_{\text {Blocos }}$ & & $5,322^{\mathrm{ns}}$ & $5,685^{\mathrm{ns}}$ & $0,959^{\text {ns }}$ \\
\hline $\mathrm{CV}(\%)$ & & 45,00 & 29,16 & 8,07 \\
\hline
\end{tabular}

ns não significativo. 
lores baixos de Kow (Rodrigues \& Almeida 2005), correspondendo, na prática, a maior solubilidade e mobilidade e menor adsorção da molécula, em solos arenosos, os quais tendem a apresentar menor teor de matéria orgânica do que os solos argilosos (Oliveira et al. 1998, Liu et al. 2001, Ohmes \& Mueller 2007, Szmigielski et al. 2009).

Biffe et al. (2010) verificaram que o S-metolachlor (1.920 $\left.\mathrm{g} \mathrm{ha}^{-1}\right)$ foi seletivo para as cultivares 'Fécula Branca' e 'Fibra', quando aplicado em pré-emergência, em condições de solo arenoso. Desta forma, pode-se constatar que a seletividade de herbicidas aplicados em pré-emergência, na cultura da mandioca, pode ser dependente do tipo de solo e da cultivar ou variedade avaliados.

De maneira geral, no presente estudo, observou-se que os herbicidas flumioxazin, sulfentrazone e S-metolachlor e as misturas clomazone + flumioxazin e sulfentrazone + S-metolachlor podem evitar a interferência das plantas daninhas na cultura da mandioca cv. 'Cascuda' por tempo superior ao período crítico de prevenção da interferência, correspondente ao período compreendido entre 25 e 90 dias após o plantio da cultura (Moura 2000, Johanns \& Contiero 2006, Albuquerque et al. 2008).

Ressalta-se o potencial de utilização das misturas em tanque de clomazone + flumioxazin e sulfentrazone + S-metolachlor, em pré-emergência da mandioca, para se explorar o efeito residual no controle do banco de sementes das plantas daninhas no solo. Destaca-se, ainda, que herbicidas seletivos à mandioca, além do clomazone, já registrado para a cultura, a exemplo do flumioxazin, sulfentrazone e S-metolachlor, podem contribuir no manejo das plantas daninhas e evitar a seleção de biótipos resistentes aos herbicidas, em áreas de cultivo de mandioca, devido à maior possibilidade de rotação dos mecanismos de ação (Beckie 2006, Beckie \& Reboud 2009, Mello et al. 2012, Vencill et al. 2012).

\section{CONCLUSÃO}

Os herbicidas apresentaram-se seletivos às plantas de mandioca cv. 'Cascuda', quando aplicados em pré-emergência. Os herbicidas flumioxazin $\left(60 \mathrm{~g} \mathrm{ha}^{-1}\right)$, sulfentrazone (600 $\left.\mathrm{g} \mathrm{ha}^{-1}\right)$, S-metolachlor (1.920 $\left.\mathrm{g} \mathrm{ha}^{-1}\right)$ e as misturas clomazone + flumioxazin $\left(900+50 \mathrm{~g} \mathrm{ha}^{-1}\right)$, clomazone + sulfentrazone $\left(900+500 \mathrm{~g} \mathrm{ha}^{-1}\right)$ e clomazone + $\mathrm{S}$-metolachlor $\left(900+1.440 \mathrm{~g} \mathrm{ha}^{-1}\right)$ foram eficientes no controle das plantas daninhas, apresentando os maiores efeitos residuais sobre o banco de sementes no solo.

\section{REFERÊNCIAS}

ALABI, B. S. et al. Giant sensitive plant interference in cassava. Weed Science, Champaign, v. 49, n. 2, p. 171176, 2001.

ALBUQUERQUE, J. A. A. et al. Interferência de plantas daninhas sobre a produtividade da mandioca (Manihot esculenta). Planta Daninha, Viçosa, v. 26, n. 2, p. 279289, 2008.

BECKIE, H. J. Herbicide-resistant weeds: management tactics and practices. Weed Technology, Champaign, v. 20, n. 3, p. 793-814, 2006.

BECKIE, H. J.; REBOUD, X. Selecting for weed resistance: herbicide rotation and mixture. Weed Technology, Champaign, v. 23, n. 3, p. 363-370, 2009.

BIFFE, D. F. et al. Avaliação de herbicidas para dois cultivares de mandioca. Planta Daninha, Viçosa, v. 28, n. 4, p. 807-816, 2010.

BORGES, M. F.; FUKUDA, W. M. G.; ROSSETTI, A. G. Avaliação de variedades de mandioca para consumo humano. Pesquisa Agropecuária Brasileira, Brasília, DF, v. 37, n. 11, p. 1559-1565, 2002.

BRAUN-BLANQUET, J. Fitosociologia: bases para el estudio de las comunidades vegetales. Madrid: H. Blume, 1979.

CHIKOYE, D.; EKELEME, F.; UDENSI, U. E. Cogongrass suppression by intercropping cover crops in corn/cassava systems. Weed Science, Champaign, v. 49, n. 5, p. 658-667, 2001.

CURCELLI, F. et al. Produção de cepa de duas variedades de mandioca em diferentes tratamentos de herbicidas. Revista Raízes e Amidos Tropicais, Botucatu, v. 6, n. 1, p. 162-172, 2010.

EMPRESA BRASILEIRA DE PESQUISA AGROPECUÁRIA (Embrapa). Centro Nacional de Pesquisa de Solos. Sistema brasileiro de classificação de solos. 2. ed. Rio de Janeiro: Embrapa, 2006.

FELIPE, F. I.; ALVES, L. R. A.; CAMARGO, S. G. C. Panorama e perspectivas para a indústria de fécula de mandioca no Brasil. Revista Raizes e Amidos Tropicais, Botucatu, v. 6, n. 1, p. 134-146, 2010.

GROSMAN, J.; FREITAS, A. C. Determinação do teor de matéria seca pelo peso específico em raízes de mandioca. Revista Agronômica, Porto Alegre, v. 14, n. 1, p. 75-80, 1950. 
INSTITUTO BRASILEIRO DE GEOGRAFIA E ESTATÍSTICA (IBGE). Levantamento sistemático da produção agrícola: pesquisa mensal de previsão e acompanhamento das safras agrícolas no ano civil. Rio de Janeiro: IBGE, 2012.

JOHANNS, O.; CONTIERO, R. L. Efeitos de diferentes períodos de controle e convivência de plantas daninhas com a cultura da mandioca. Revista Ciência Agronômica, Fortaleza, v. 37, n. 3, p. 326-331, 2006.

KELLY, S. T.; SHANKLE, M. W.; MILLER, D. K. Efficacy and tolerance of flumioxazin on sweetpotato (Ipomoea batatas). Weed Technology, Champaign, v. 20, n. 2, p. 334-339, 2006.

LIU, W. P. et al. Adsorption of chloroacetanilide herbicides on soil: I. Structural influence of chloroacetanilide herbicide for their adsorption on soils and its components. Journal of Environmental Sciences, Beijing, v. 13, n. 1, p. 37-45, 2001.

MELO, M. S. C. et al. Alternativas para o controle químico de capim-amargoso (Digitaria insularis) resistente ao glyphosate. Revista Brasileira de Herbicidas, Maringá, v. 11, n. 2, p. 195-203, 2012.

MOURA, G. M. Interferência de plantas daninhas na cultura de mandioca (Manihot esculenta) no Estado do Acre. Planta Daninha, Viçosa, v. 18, n. 3, p. 451-456, 2000.

MUELLER-DOMBOIS, D.; ELLENBERG, H. Aims and methods of vegetation ecology. New York: John Wiley \& Sons, 1974.

OHMES, G. A.; MUELLER, T. C. Sulfentrazone adsorption and mobility in surface soil of the southern United States. Weed Technology, Champaign, v. 21, n. 3, p. 796-800, 2007.

OLIVEIRA, M. F. et al. Atividade dos herbicidas flumioxazin e metribuzin em diferentes solos. Planta Daninha, Viçosa, v. 16, n. 1, p. 37-43, 1998.
OLIVEIRA JÚNIOR, R. S. et al. Manejo químico de plantas daninhas em área de plantio direto de mandioca. Revista Brasileira de Herbicidas, Maringá, v. 2, n. 3, p. 99-106, 2001.

PERESSIN, V. A. et al. Acúmulo de matéria seca na presença e na ausência de plantas infestantes no cultivar de mandioca SRT59 - Branca de Santa Catarina. Bragantia, Campinas, v. 57, n. 1, p. 135-148, 1998.

RODRIGUES, B. N.; ALMEIDA, F. S. Guia de herbicidas. 5. ed. Londrina: Ed. dos Autores, 2005.

SILVA, D. V. et al. Manejo de plantas daninhas na cultura da mandioca. Planta Daninha, Viçosa, v. 30, n. 4, p. 901910, 2012.

SILVA, F. M. L. et al. Moléculas de herbicidas seletivos à cultura da mandioca. Revista Trópica: Ciências Agrárias e Biológicas, Chapadinha, v. 3, n. 2, p. 61-72, 2009.

SILVEIRA, H. M. et al. Sensibilidade de cultivares de mandioca ao herbicida mesotrione. Revista Brasileira de Herbicidas, Maringá, v. 11, n. 1, p. 24-31, 2012.

SOCIEDADE BRASILEIRA DA CIÊNCIA DAS PLANTAS DANINHAS (SBCPD). Procedimentos para instalação, avaliação e análise de experimentos com herbicidas. Londrina: SBCPD, 1995.

SZMIGIELSKI, A. M. et al. Development of a laboratory bioassay and effect of soil properties on sulfentrazone phytotoxicity in soil. Weed Technology, Champaign, v. 23, n. 3, p. 486-491, 2009.

VELINI, E. D. et al. Avaliação da seletividade da mistura de oxyfluorfen e ametryne, aplicada em pré ou pósemergência, a dez variedades de cana-de-açúcar (canaplanta). Planta Daninha, Viçosa, v. 18, n. 1, p. 123-134, 2000.

VENCILL, W. K. et al. Herbicide resistance: towards an understanding of resistance development and the impact of herbicide-resistant crops. Weed Science, Champaign, v. 60, n. esp., p. 2-30, 2012. 